\title{
Deposition of titanium nitride thin films at low temperatures by CVD using metalorganic and organometallic titanium compounds as precursors
}

\author{
C.I.M.A. SPEE, J.L. LINDEN, E.A. VAN DER ZOUWEN-ASSINK, K. TIMMER, F. VERBEEK, \\ H.A. MEINEMA, D.M. FRIGO* and S. VAN DER VEN*
}

TNO Plastics and Rubber Research Institute, TNO Industrial Research, P.O. Box 108, 3700 AC Zeist, The Netherlands

*Billiton Research B.V., P.O. Box 40,6800 AA Arnhem, The Netherlands

\begin{abstract}
A series of titanium compounds, Ti( $\left(\mathrm{NMe}_{2}\right)_{4}, \quad \mathrm{t}-\mathrm{BuTi}\left(\mathrm{NMe}_{2}\right)_{3}, \quad\left[\mathrm{Ti}(\mu-\mathrm{N}-\mathrm{t}-\mathrm{Bu})(-\mathrm{NMe})_{2}\right]_{2}$, $\mathrm{Ti}(\mathrm{t}-\mathrm{BuDAD})_{2}$ and $\mathrm{CpTiC}_{7} \mathrm{H}_{7}$, have been screened in combination with $\mathrm{NH}_{3}$ for their suitability as precursors for the CVD of titanium nitride films at substrate temperatures of $300-600^{\circ} \mathrm{C}$ and a system pressure of 1.5 Torr. The best $\mathrm{TiN}$ layers have been grown using $\mathrm{t}-\mathrm{BuTi}\left(\mathrm{NMe}_{2}\right)_{3}$ and $\mathrm{NH}_{3}$, from which an $0.8 \mu \mathrm{m}$ thick layer deposited at $400^{\circ} \mathrm{C}$, showed a resistivity of $1.4 \cdot 10^{-3} \Omega \cdot \mathrm{cm}$ and contained 5 atom $\%$ carbon and 6 atom\% oxygen.
\end{abstract}

\section{1 - INTRODUCTION}

In integrated circuit technology sputter techniques are generally used for metallization processes. For dimensions smaller than roughly $1 \mu \mathrm{m}$ the limited step coverage of sputter processes makes it difficult to fill vias and contact holes in a reliable way. Metallization by Chemical Vapour deposition (CVD) has also been studied extensively for tungsten, aluminium and/or copper $/ 1 /$. However, sometimes a diffusion barrier and/or nucleation layer between the metal and silicon is necessary. Sputtered TiN is widely accepted for such purposes /2-3/. However, in decreasing feature sizes, also for TiN a CVD process is required.

CVD of $\mathrm{TiN}$ using $\mathrm{TiCl}_{4}$ and $\mathrm{NH}_{3}$ has been widely studied. However, layers of a quality that is acceptable for semiconductor applications i.e. contain sufficiently low levels of $\mathrm{Cl}$, are only deposited at temperatures above $540^{\circ} \mathrm{C}$, which is too high for IC applications /4-5/. Several groups have reported TiN deposition by CVD at temperatures below $450^{\circ} \mathrm{C}$ using metalorganic precursors, in particular tetrakis(dimethylamido)titanium, $\mathrm{Ti}\left(\mathrm{NMe}_{2}\right)_{4}$ and tetrakis(diethylamido)titanium, $\mathrm{Ti}\left(\mathrm{NEt}_{2}\right)_{4}$. TiN layers deposited from these precursors contain significant amounts of carbon and oxygen impurities $/ 6-8 /$. The best layers reported have been deposited using $\mathrm{Ti}\left(\mathrm{NEt}_{2}\right)_{4}$ and $\mathrm{NH}_{3}$ and contained $<3 \% \mathrm{C}$ and $<0.5 \% \mathrm{O}$ and possessed layer resistivities as low as $200 \mu \Omega \cdot \mathrm{cm} / 9 /$.

In this paper we report investigations into the suitability of a series of metalorganic and organometallic titanium compounds to deposit $\mathrm{TiN}$ at temperatures below $500^{\circ} \mathrm{C}$. These compounds have been tested in conjunction with $\mathrm{NH}_{3}$ as a nitrogen source. Each compound has been screened under various conditions in a series of 5-10 MOCVD experiments. 


\section{2 - EXPERIMENTAL}

\subsection{Synthesis of titanium compounds}

t-Butyltris(dimethylamido)titanium, t-BuTi( $\left(\mathrm{NMe}_{2}\right)_{3} \quad$ (orange liquid; bp 49.5$51^{\circ} \mathrm{C} / 0.06$ Torr) and cyclopentadienylcycloheptatrienyltitanium, $\mathrm{CpTiC}_{7} \mathrm{H}_{7}$ (blue solid; sublimes at $130^{\circ} \mathrm{C} / 0.1$ Torr) were synthesised according to literature procedures $/ 8,10 /$;

A commercial sample of Ti( $\left.\mathrm{NMe}_{2}\right)_{4}$ (Merck; 95\%) was purified to remove chloride as follows. A sample of $56 \mathrm{~g}$ of orange-coloured Ti( $\left(\mathrm{NMe}_{2}\right)_{4}$ was treated with $0.5 \mathrm{~g}$ of sodium metal. The mixture was stirred for $1 \mathrm{hr}$ at room temperature and kept overnight. The dark-brown liquid thus obtained was distilled to give $53 \mathrm{~g}$ of $\mathrm{Ti}\left(\mathrm{NMe}_{2}\right)_{4}$ containing $0.37 \% \mathrm{Cl}$. Stirring this sample overnight with $\mathrm{LiNMe}_{2}(5.1 \mathrm{~g})$ followed by distillation at $43-45^{\circ} \mathrm{C} / 0.1$ Torr gave a sample of $\mathrm{Ti}\left(\mathrm{NMe}_{2}\right)_{4}(51 \mathrm{~g}$; yellow liquid), the $\mathrm{Cl}$ content of which was below detection limits $(0.2 \mathrm{wt} \%)$.

A sample of bis(N,N'-ditertbutyl-1,4-diaza-1,3-butadiene)titanium, Ti(t-BuDAD) ${ }_{2}$ (black-brown solid) was obtained from the group of Dieck, Univ. of Hamburg, Germany. A sample of bis(dimethylamido)( $\mu$-t-butylimido)titanium(IV)dimer, $\left[\mathrm{Ti}(\mu-\mathrm{N}-\mathrm{t}-\mathrm{Bu})(-\mathrm{NMe})_{2}\right]_{2}$ (dark red solid) was obtained from the group of Teuben, Univ. of Groningen, The Netherlands.

\subsection{Deposition system}

The MOCVD reactor is a load-locked, stagnantflow, cold-wall reactor. The base pressure was around $5 \cdot 10^{-3}$ Torr; the operating pressure was 1.5 Torr. The substrates sat on a stainless-steel table heated by an induction coil connected to an RF-generator. The susceptor temperature was measured by a thermocouple inserted directly in the table. The surface temperature of the samples can not be measured directly but will be lower than that of the susceptor. The substrates used were $1 \mathrm{~cm}^{2}$ samples cut from a (100) Si wafer. The precursors were evaporated in a bubbler-type system and carried to the reactor in a nitrogen gas stream $(0.6 \mathrm{l} / \mathrm{h}$ (STP)), where they were mixed in a nozzle at the top of the stagnant flow reactor with nitrogen and $\mathrm{NH}_{3}$. The nitrogen used (99.999\%) was purified by a Supelchem purifier $\left(\mathrm{O}_{2}\right.$ and $\mathrm{H}_{2} \mathrm{O}$ both $\left.<0.1 \mathrm{ppm}\right)$. U.L.S.I. quality $\mathrm{NH}_{3}$ (Air Liquide) has been used $\left(\mathrm{O}_{2}\right.$ and $\mathrm{H}_{2} \mathrm{O}$ both $\left.<1 \mathrm{ppm}\right)$. Throughout the experiments the total gas flow was $18 \mathrm{l} / \mathrm{h}$ (STP).

\subsection{Film characterization}

Layer thicknesses were determined by depth profiling with sputtering. Density of the layers was calculated from the weight gain of the samples in combination with the layer thickness. For a few samples the layer thickness could not be measured accurately. The resistivities of the samples were determined by 4-point van der Pauw measurements. For samples where the exact thickness could not be measured an error bar has been included in the resistivity data.

Oxygen and carbon impurities have been determined by Auger Electron Spectroscopy (AES). A few samples also have been analysed by Röntgen MicroAnalyses (RMA). The Auger analysis data have been calibrated on the basis of the RMA analysis. 


\section{3 - RESULTS AND DISCUSSION}

\subsection{Growth rate and kinetics}

The deposition rates of the TiN layers vs. reciprocal temperature are shown in Fig. 1. For each precursor system for a number of representative experiments the deposition conditions and analyses data of the deposited layers are given in Table 1. For the $\left[\mathrm{Ti}(\mu-\mathrm{N}-\mathrm{t}-\mathrm{Bu})\left(\mathrm{NMe}_{2}\right)_{2}\right]_{2} / \mathrm{NH}_{3}$, the $\mathrm{Ti}(\mathrm{t}-\mathrm{BuDAD})_{2} / \mathrm{NH}_{3}$ and the $\mathrm{CpTiC}_{7} \mathrm{H}_{7} / \mathrm{NH}_{3}$ systems, the growth rate appears to be dependent upon deposition temperature, which indicates that the rate is determined by the kinetics of the decomposition. In contrast the $\mathrm{Ti}\left(\mathrm{NMe}_{2}\right)_{4} / \mathrm{NH}_{3}$ and the t-BuTi(NMe$)_{3} / \mathrm{NH}_{3}$ systems show only a very small dependence of growth rate from deposition temperature, which suggests they are limited by mass transport. The growth rates of TiN deposition from Ti(t-BuDAD) $)_{2} / \mathrm{NH}_{3}$ and $\mathrm{CpTiC}_{7} \mathrm{H}_{7} / \mathrm{NH}_{3}$ only become noticeable at temperatures above $500^{\circ} \mathrm{C}$. For this reason, for IC applications where growth temperatures may not exceed $450^{\circ} \mathrm{C}$, these last two systems are not applicable due to the low growth rates.

\subsection{Morphology and structure}

The deposited layers showed a range of colors from gold for very thin coatings $(70 \mathrm{~nm})$ to black for relatively thick coatings $(\geq 1 \mu \mathrm{m})$. The density of the layers especially those deposited by the $\mathrm{Ti}\left(\mathrm{NMe}_{2}\right)_{4} / \mathrm{NH}_{3}$ and the t-BuTi( $\left(\mathrm{NMe}_{2}\right)_{3} / \mathrm{NH}_{3}$ systems is very low. On some of the samples XRD showed only very broad TiN peaks, indicating the presence of very smallgrained material. Analysis of thick layers

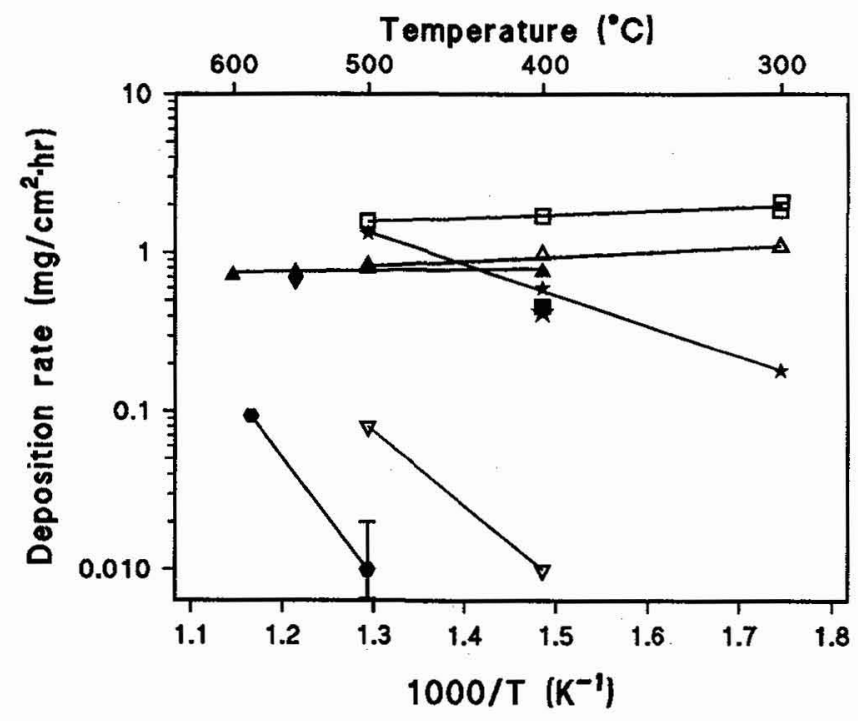

Fig. 1. Deposition rate vs reciprocal susceptor temperature for various titanium precursors, , $=\mathrm{Ti}\left(\mathrm{NMe}_{2}\right)_{4} ; \quad \Delta, \wedge \mathrm{t}-\mathrm{BuTi}\left(\mathrm{NMe}_{2}\right)_{3}$;

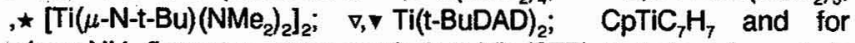
various $\mathrm{NH}_{3}$ flowrates, open symbols $6 \mathrm{I} / \mathrm{h}$ (STP) and closed symbols $17.4 \mathrm{l} / \mathrm{h}$ (STP). 
TABLE 1. Experimental conditions and analysis results of deposited layers for MOCVD experiments with a series of TiN precursors: 1) Ti( $\left.\left(\mathrm{NMe}_{2}\right)_{4} ; 2\right)$ t-BuTi $\left.\left(\mathrm{NMe}_{2}\right)_{3} ; 3\right)\left[\mathrm{Ti}(\mu-\mathrm{N}-\mathrm{t}-\mathrm{Bu})\left(\mathrm{NMe}_{2}\right)_{2}\right]_{2}$; 4) $\mathrm{Ti}(\mathrm{t}-\mathrm{BuDAD})_{2}$; 5) $\mathrm{CpTiC}_{7} \mathrm{H}_{7}$.

\begin{tabular}{lllllllllll}
\hline prec. & $\begin{array}{l}\text { temp. of } \\
\text { precursor } \\
\left({ }^{\circ} \mathrm{C}\right)\end{array}$ & $\begin{array}{l}\mathrm{NH}_{3} \text {-flow } \\
(\mathrm{I} / \mathrm{h} \text { STP) })\end{array}$ & $\begin{array}{l}\text { temp. of } \\
\text { susceptor } \\
\left({ }^{\circ} \mathrm{C}\right)\end{array}$ & $\begin{array}{l}\text { layer } \\
\text { thickness } \\
(\mu \mathrm{m})\end{array}$ & $\begin{array}{l}\text { growth } \\
\text { rate } \\
(\mu \mathrm{m} / \mathrm{h})\end{array}$ & $\begin{array}{l}\text { density } \\
(\%)\end{array}$ & $\begin{array}{l}\text { resistivity } \\
(\Omega \cdot \mathrm{cm})\end{array}$ & $\begin{array}{l}\mathrm{AES}^{1} \\
\mathrm{C}, \\
\text { at\% }\end{array}$ & $\begin{array}{l}\text { O, } \\
\text { at\% }\end{array}$ & color \\
\hline 1 & 22 & 6 & 400 & 3.6 & 7.2 & 47 & $1.8 \cdot 10^{-2}$ & 5 & 13 & black \\
1 & 0 & 1.08 & 400 & 0.99 & 1.98 & 40 & $1.0 \cdot 10^{-2}$ & 6 & 14 & black \\
1 & 0 & 17.4 & 400 & 0.99 & 1.98 & 44 & $4.1 \cdot 10^{-3}$ & 5 & 9 & black \\
2 & 20 & 6 & 400 & 0.76 & 3.04 & 61 & $1.9 \cdot 10^{-3}$ & 6 & 7 & brown \\
2 & 20 & 17.4 & 400 & 0.80 & 3.20 & 45 & $1.4 \cdot 10^{-3}$ & 5 & 6 & brown \\
2 & 20 & 17.4 & 600 & 0.14 & 1.68 & 2 & $3.2 \cdot 10^{-3}$ & 4 & 27 & purple/brown \\
3 & 100 & 17.4 & 300 & 0.13 & 0.78 & 2 & $4.8 \cdot 10^{-2}$ & 9 & 20 & blue/green \\
3 & 100 & 17.4 & 400 & 0.07 & 0.84 & 2 & $2.1 \cdot 10^{-3}$ & 6 & 17 & blue/green \\
4 & 140 & 17.4 & 500 & 0.07 & 0.05 & 2 & $1.6 \cdot 10^{-3}$ & 6 & 23 & gold \\
4 & 140 & 17.4 & 585 & 0.42 & 0.28 & 64 & $1.5 \cdot 10^{-3}$ & 8 & 17 & brown \\
4 & 140 & 17.4 & 625 & 0.08 & 0.24 & 2 & $9.6 \cdot 10^{-4}$ & 11 & 14 & gold/pink \\
5 & 98 & 6 & 500 & 0.18 & 0.24 & 89 & $5.9 \cdot 10^{-3}$ & \pm 10 & 15 & green/pink \\
5 & 80 & 17.4 & 550 & 0.21 & 1.26 & 100 & $4.9 \cdot 10^{-3}$ & 4 & 8 & brown \\
\hline
\end{tabular}

deposited by $\mathrm{Ti}\left(\mathrm{NMe}_{2}\right)_{4} / \mathrm{NH}_{3}$ at $400^{\circ} \mathrm{C}$ and by t-BuTi(NMe $)_{3} / \mathrm{NH}_{3}$ at $500^{\circ} \mathrm{C}$ by RBS(ERD), showed a considerable amount of $H$ to be present (up to 14 at\%). Outgassing experiments were performed on a sample, deposited by the $\mathrm{Ti}\left(\mathrm{NMe}_{2}\right)_{4} / \mathrm{NH}_{3}$ system at $400^{\circ} \mathrm{C}$. The sample was heated to $700^{\circ} \mathrm{C}$ in vacuo, whereupon it liberated considerable amounts of $\mathrm{NH}_{3}$ and small amounts of carbon containing species $\left(\mathrm{HCN}, \mathrm{CH}_{3} \mathrm{CN}\right.$ and $\left.(\mathrm{CN})_{2}\right)$. Most probably, these thick layers contained a small amount of partially decomposed precursor. The layers deposited using the $\mathrm{CpTiC}_{7} \mathrm{H}_{7} / \mathrm{NH}_{3}$ system are very dense. XRD analyses of one of the layers deposited with this system showed peaks of (100) oriented crystalline TiN.

\subsection{Impurities}

Numerous samples have been analysed by AES, as shown in figures 2 and 3; two samples have also been analysed by RMA. The results showed equal amounts of oxygen, but less than half the amount of carbon detected by RMA than by AES. As RMA is a much more accurate technique for quantification of the carbon and oxygen contents, the AES carbon atom percentages have been calibrated accordingly.

The lowest values found for carbon content were with the $\mathrm{Ti}\left(\mathrm{NMe}_{2}\right)_{4} / \mathrm{NH}_{3}$ and t-BuTi( $\left(\mathrm{NMe}_{2}\right)_{3} / \mathrm{NH}_{3}$ system, namely, 4-5 atom\%. For these systems the carbon content is almost independent of deposition temperature and $\mathrm{NH}_{3} / \mathrm{Ti}$-precursor ratio. In contrast layers deposited with $\mathrm{CpTiC}_{7} \mathrm{H}_{7}$ and $\mathrm{NH}_{3}$ showed a dramatic decrease of carbon content with susceptor temperature. Unfortunately the growth rate at temperatures below $500^{\circ} \mathrm{C}$ was too low to examine this trend further. A possible cause for this decrease in carbon content at lower susceptor temperatures is that the decomposition fragments from the $\mathrm{Cp}$ and $\mathrm{C}_{7} \mathrm{H}_{7}$ ligands themselves decompose at higher temperature; resulting in more carbon-rich TiN layers. The layers deposited using $\left[\mathrm{Ti}(\mu-\mathrm{N}-\mathrm{t}-\mathrm{Bu})\left(\mathrm{NMe}_{2}\right)_{2}\right]_{2}$ and $\mathrm{NH}_{3}$ also showed a decrease of carbon content, but with increasing temperature. Unfortunately layers deposited at higher susceptor temperatures showed extensive cracking, so it was not possible to 


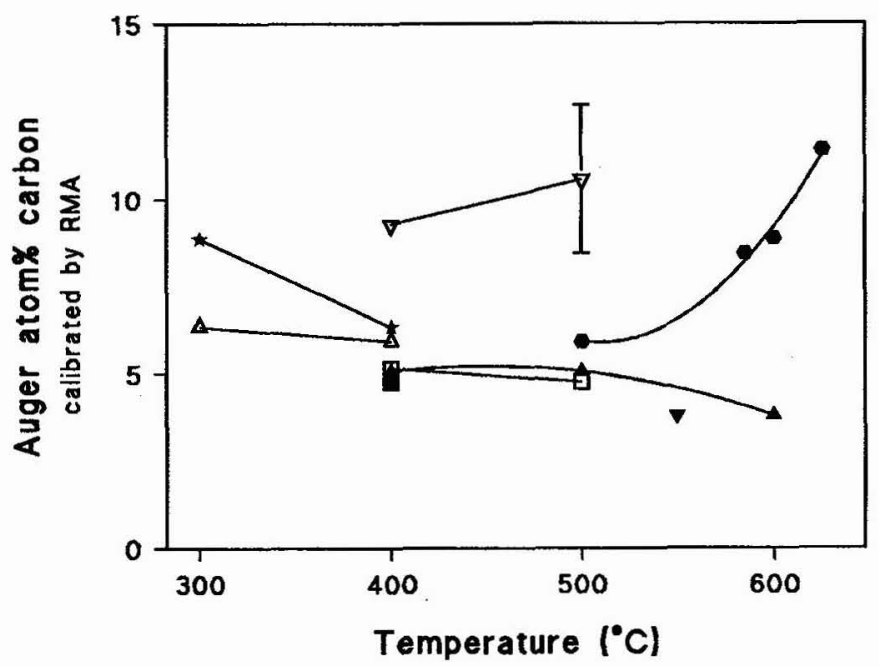

Fig. 2. Carbon impurities in TiN layers determined by AES as a function of susceptor temperature for various titanium precursors, ,- Ti( $\left(\mathrm{NMe}_{2}\right)_{4} ; \quad \Delta, \mathbf{t} \mathrm{t}-\mathrm{BuTi}\left(\mathrm{NMe}_{2}\right)_{3} ; \quad, \star\left[\mathrm{Ti}(\mu-\mathrm{N}-\mathrm{t}-\mathrm{Bu})\left(\mathrm{NMe}_{2}\right)_{2}\right]_{2} ;$ $\nabla, \nabla \mathrm{T}(\mathrm{t}-\mathrm{BuDAD})_{2} ; \quad \mathrm{CpTiC}_{7} \mathrm{H}_{7}$ and various $\mathrm{NH}_{3}$ flowrates, open symbols $6 \mathrm{I} / \mathrm{h}$ (STP) and closed symbols $17.4 \mathrm{l} / \mathrm{h}$ (STP).

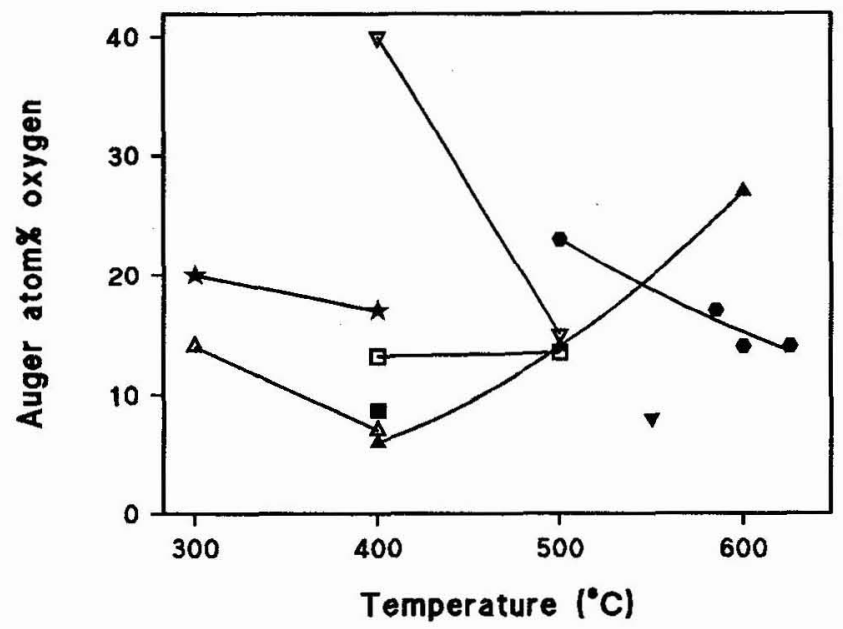

Fig. 3. Oxygen impurities in TiN layers determined by AES as a function of susceptor temperature for various titanium precursors, ,- $\left.\mathrm{Ti}\left(\mathrm{NMe}_{2}\right)_{4} ; \quad \Delta_{1} \wedge \mathrm{t}-\mathrm{BuTi}\left(\mathrm{NMe}_{2}\right)_{3} ; \quad, \star \mathrm{Ti}(\mu-\mathrm{N}-\mathrm{t}-\mathrm{Bu})\left(\mathrm{NMe}_{2}\right)_{2}\right]_{2} ;$ $\nabla, \nabla \mathrm{Ti}(\mathrm{t}-\mathrm{BuDAD})_{2} ; \quad \mathrm{CpTiC}_{3} \mathrm{H}_{7}$ and various $\mathrm{NH}_{3}$ flowrates, open symbols $6 \mathrm{I} / \mathrm{h}$ (STP) and closed symbols $17.4 \mathrm{l} / \mathrm{h}$ (STP). 
determine the trend of carbon content at higher susceptor temperatures. Possibly the precursor does not decompose completely at low susceptor temperatures.

The amount of oxygen found in the layers is on average higher than that of carbon. The lowest value is 6 atom\% of oxygen in a TiN layer deposited by the t-BuTi $\left(\mathrm{NMe}_{2}\right)_{3} / \mathrm{NH}_{3}$ system. In a given layer, the AES depth profiles showed a fairly constant ratio of carbon and oxygen in the TiN layer from just under the surface to the interface with the silicon substrate. The surfaces of all layers show higher oxygen levels, indicating that oxidation of the surface, due to contact of the layers with air has taken place. A few samples show a decrease of oxygen from the surface to the interface. This observation combined with the observation of an increase of resistivity with time, has resulted in the conclusion that at least some of the deposited TiN layers might be oxidised by air, in the period between CVD and AES analysis. Therefore only tentative conclusions can be drawn from figure 3 . Three TiN deposition systems showed a large dependence of oxygen content with susceptor temperature, t-BuTi( $\left(\mathrm{NMe}_{2}\right)_{3} / \mathrm{NH}_{3}$, which showed a minimum oxygen content at about $400^{\circ} \mathrm{C}$, and $\mathrm{CpTiC}_{7} \mathrm{H}_{7} / \mathrm{NH}_{3}$ and Ti(t-BuDAD) $2 / \mathrm{NH}_{3}$ which showed a dramatic decrease at higher temperatures. For the $\mathrm{Ti}\left(\mathrm{NMe}_{2}\right)_{4} / \mathrm{NH}_{3}$ system, which showed almost no dependence of oxygen content upon susceptor temperature, a large decrease of oxygen content was observed with an increase of the $\mathrm{NH}_{3} / \mathrm{Ti}\left(\mathrm{NMe}_{2}\right)_{4}$ ratio.

\subsection{Resistivity}

The electrical resistivity of every TiN layer deposited was measured within a few minutes of deposition. The resistivity of some samples was found to change in time, probably due to oxidation. The resistivity of a large number of TiN layers could not be determined, either because the exact layer thickness could not be determined or because the layer was cracked. Resistivity values that could be determined are given in figure 4 . The trends in the resistivity of deposited TiN layers vs susceptor temperature are almost identical to those for oxygen content of the layers; hardly any correlation with carbon content was observed. This is not unexpected if the carbon is present as $\mathrm{TiC}$ because this is almost as conductive as $\mathrm{TiN}$, where $\mathrm{TiO}_{2}$ is an excellent insulator. For the $\mathrm{Ti}\left(\mathrm{NMe}_{2}\right)_{4} / \mathrm{NH}_{3}$ system the resistivity of the TiN layers can be improved considerably by using a large ratio of $\mathrm{NH}_{3}$ to $\mathrm{Ti}\left(\mathrm{NMe}_{2}\right)_{4}$, which seems to decrease the amount of oxygen incorporated. The results obtained with the $\mathrm{Ti}\left(\mathrm{NMe}_{2}\right)_{4} / \mathrm{NH}_{3}$ system agree with the observations reported in literature $/ 7,11 /$. The best resistivity values at susceptor temperatures below $500^{\circ} \mathrm{C}$ were found with the t-BuTi $\left(\mathrm{NMe}_{2}\right)_{3} / \mathrm{NH}_{3}$ system. TiN layers with a resistivity of about $1 \mathrm{mOhm} \cdot \mathrm{cm}$ at a deposition susceptor temperature around $450^{\circ} \mathrm{C}$ have been obtained. As explained in the previous paragraph the layers deposited with the $\left[\mathrm{Ti}(\mu-\mathrm{N}-\mathrm{t}-\mathrm{Bu})\left(\mathrm{NMe}_{2}\right)_{2}\right]_{2} / \mathrm{NH}_{3}$ system at susceptor temperatures above $400^{\circ} \mathrm{C}$ showed cracking in even the thinnest deposited layers. Extrapolating the large decrease of layer resistivity between 300 and $400^{\circ} \mathrm{C}$, this system might have given the lowest resistivities at susceptor temperatures of $450^{\circ} \mathrm{C}$.

The best resistivities obtained, for layers with thicknesses of about $1 \mu \mathrm{m}$, are about an order of magnitude higher than bulk TiN, but are lower than resistivities reported in literature for TiN layers with comparable thicknesses $/ 7,8,11 /$. 


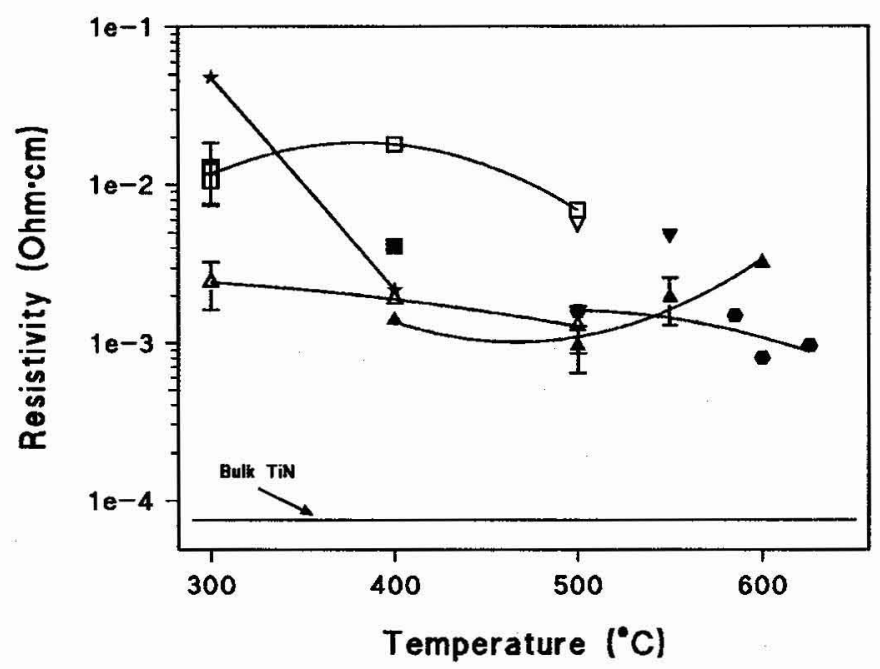

Fig. 4. Resistivity of deposited TiN layers as a function of susceptor temperature for various titanium precursors, , $\mathrm{Ti}\left(\mathrm{NMe}_{2}\right)_{4}$; $\Delta, \Delta \mathrm{t}-\mathrm{BuTi}\left(\mathrm{NMe}_{2}\right)_{3} ; \quad$, $\left[\mathrm{Ti}(\mu-\mathrm{N}-\mathrm{t}-\mathrm{Bu})\left(\mathrm{NMe}_{2}\right)_{2}\right]_{2} ; \quad \nabla, \nabla \mathrm{Ti}(\mathrm{t}-\mathrm{BuDAD})_{2}$; $\mathrm{CpTiC}_{7} \mathrm{H}_{7}$ and various $\mathrm{NH}_{3}$ flowrates, open symbols $6 \mathrm{I} / \mathrm{h}$ (STP) and closed symbols $17.4 \mathrm{I} / \mathrm{h}$ (STP).

\section{4 - CONCLUSIONS}

TiN films, up to a few $\mu \mathrm{m}$, have been deposited at low temperatures $\left(300-600^{\circ} \mathrm{C}\right)$ and low pressures (1.5 Torr) on Si using the organotitanium compounds $\mathrm{Ti}\left(\mathrm{NMe}_{2}\right)_{4}$, t-BuTi $\left(\mathrm{NMe}_{2}\right)_{3}, \quad\left[\mathrm{Ti}(\mu-\mathrm{N}-\mathrm{t}-\mathrm{Bu})\left(\mathrm{NMe}_{2}\right)_{2}\right]_{2}, \mathrm{Ti}(\mathrm{t}-\mathrm{BuDAD})_{2}$ and $\mathrm{CpTiC}_{7} \mathrm{H}_{7}$ in combination with a large excess of $\mathrm{NH}_{3}$. The results obtained show the generally used Ti( $\left(\mathrm{NMe}_{2}\right)_{4} / \mathrm{NH}_{3}$ system to be among the least favourable based on the criterium of a comparison of the resistivities, although this could be improved by using a very large excess of $\mathrm{NH}_{3}$ to $\mathrm{Ti}\left(\mathrm{NMe}_{2}\right)_{4}$. The $\left[\mathrm{Ti}(\mu-\mathrm{N}-\mathrm{t}-\mathrm{Bu})\left(\mathrm{NMe}_{2}\right)_{2}\right]_{2} / \mathrm{NH}_{3}$ system showed interesting results with susceptor temperatures around $400^{\circ} \mathrm{C}$, but at higher temperatures considerable cracking was observed probably due to a large amount of stress in the TiN layers. The small number of experiments with this system make conclusions rather tentative. The $\mathrm{CpTiC}_{7} \mathrm{H}_{7} / \mathrm{NH}_{3}$ system shows interesting results as regard to the resistivity of deposited TiN layers, but unfortunately the growth rate at temperatures below $500^{\circ} \mathrm{C}$ is too low. The best results have been obtained with the t-BuTi $\left(\mathrm{NMe}_{2}\right)_{3} / \mathrm{NH}_{3}$ system, which, even with the relatively thick layers and the relatively high background pressure in the MOCVD test system, gave TiN layers with relatively low resistivity. Following the initial experiments described in this paper a large series of experiments using the t-BuTi $\left(\mathrm{NMe}_{2}\right)_{3} / \mathrm{NH}_{3}$ system have been performed in a specially designed apparatus for deposition of TiN at ASM, The Netherlands, and have been compared with the $\mathrm{Ti}\left(\mathrm{NMe}_{2}\right)_{4} / \mathrm{NH}_{3}$ system. These experiments have confirmed the superiority of the t-BuTi $\left(\mathrm{NMe}_{2}\right)_{3} / \mathrm{NH}_{3}$ system over the $\mathrm{Ti}\left(\mathrm{NMe}_{2}\right)_{4} / \mathrm{NH}_{3}$ system. TiN layers have been observed using 
t-BuTi $\left(\mathrm{NMe}_{2}\right)_{3} / \mathrm{NH}_{3}$ that were gold coloured (for layers up to several hundred Ångstrom thick) adherent to a wide range of substrates, chemically resistant, very hard, and showed resistivities below $300 \mu \Omega \mathrm{cm} / 12 /$.

\section{5 - ACKNOWLEDGEMENT}

This work was supported by the Netherlands Ministry of Economic Affairs in the framework of the Joint European Submicron Silicon (JESSI) programme. The authors would like to thank $C$. Mutsaerts from Philips for his help with the AES the RBS(ERD) and the outgassing analyses.

\section{6 - REFERENCES}

/1/ Workshops on Tungsten and Other Advanced Metals for VLSI/ULSI Applications I-VI, Material Research Society Symp. Proc., Material Research Society, Pittsburgh, PA, 1985-1990, and references cited therein.

/2/ Gupta S., Song J-S. and Ramachandran V., Semicond. Int., 10 (1989) p. 8087.

13/ Hems J., Semicond. Int., 11 (1990) p. 100-102.

14/ Akahori T., Tanihara A. and Tano M., Jap. J. Appl. Phys., 30 (1991) p. 3558.

15/ Buiting M.J., Otterloo A.F. and Montree A.H., J. Electrochem. Soc., 138 (1991) p. 500-505.

16/ Katz A., Feingold A., Pearton S.J., Nakahara S., Ellington M., Chakrabarti U.K., Geva M. and Lane E., J. Appl. Phys., 70 (1991) p. 3666-3677.

17/ Ishihara K., Yamazaki K., Hamada H., Kamisako K. and Tarui Y., J. Appl. Phys., 10 (1990) p. 2103-2105.

/8/ Fix R.M., Gordon R.G. and Hoffman D.M., Chem. Mater., 2 (1990) p. 235-241.

19/ Raaijmakers I.J., Vrtis R.N., Sandhu G.S., Yang J., Broadbent E.K., Roberts D.A. and Lagendijk A., Proc. Ninth Int. IEEE VLSI Multilevel Interconnection Conference, Santa Clara, CA, (1992).

/10/ Demerseman B., Dixheuf P.N., Douglade J. and Mercier R., Inorg. Chem., 21 (1982) p. 3942-3947.

111/ Katz A., Feingold A., Nakahara S., Pearton S.J., Lane E., Geva M., stevie F.A. and Jones K., J. Appl. Phys., 71 (1992) p. 993-1000.

/12/ Kuypers A.D., internal ASMI-AMTC activity report, October 1992. 